\title{
Left hand index finger predominance of Quincke pulse
}

\author{
(D) Steven H. Yale, ${ }^{1}$ (D) Halil Tekiner, ${ }^{2}$ (D) Eileen S. Yale, ${ }^{3}$ (D) Joseph J. Mazza ${ }^{4}$ \\ ${ }^{1}$ University of Central Florida College of Medicine, Orlando, USA \\ 2Department of History of Medicine and Ethics, Erciyes University Faculty of Medicine, Kayseri, Turkey \\ ${ }^{3}$ Department of General Internal Medicine, University of Florida, Gainesville, USA \\ ${ }^{4}$ Marshfield Clinic Research Institute, Wisconsin, USA
}

Cite this article as: Yale SH, Tekiner H, Yale ES, Mazza JJ. Left hand index finger predominance of Quincke pulse. North Clin Istanb 2020;7(4):415-416.

Q uincke pulse is an eponymous sign first described by Heinrich Irenaeus Quincke (1842-1922), in his paper titled "Beobachtungen über Capillar- und Venenpuls" (Observations on the capillary and venous pulse), published in 1868 [1]. As reported by Quincke:

One notices on bis/her own fingernails or on another person, the capillary pulse located at the border between the more whitish, blood-poor area and a redder more intensely injected portion of the capillary system of the nail-bed. In the majority of the persons examined, one will observe a forward and backward movement of the border of the red and white parts synchronized with the heartbeat. $\mathrm{He} /$ she should convince themselves that the increase in redness occurs a moment later than the apex beat, but still distinctly systolic and rather rapid, while the retreat of the border of the redness occurs more slowly. The behavior of the wave is perceptible to the eye [1, p. 357].

We have identified four images, three men and one woman, published on Quincke pulse found in patients with aortic insufficiency since 2013, all involving the left hand [2, 3]. Two images were published as a clinical image in NEJM (2013 and 2018, references upon request). Three of the four images were of the index finger (one also the thumb), while the other image was not specified (personal communication). Quincke rec-
ognized,"In general, it is impossible to specify which of the fingernails this finding is more clearly seen, but most often it is the index finger. [...] [However,] not every fingernail shows the mentioned white zone, general blood-supply, strong and frequent action of the heart, and high arterial pressure [1, p. 357]." He found that it was absent in the toenails, a finding which he attributed to the longer arterial course and higher hardness and thickness of the nail [1].

The different locations identified may be influenced by local and regional factors that lead to alteration in capillary blood flow, blood volume, vasomotor reflexes, and elasticity of the arterial vessels, all of which results in secondary variations in nail thickness [4]. Using a 20 $\mathrm{MHz}$ ultrasound, Wollina et al., in their study with 34 healthy subjects and 37 patients with nail disease found that the mean nail thickness varied between $0.397 \mathrm{~mm}$ (left fifth finger) and $0.481 \mathrm{~mm}$ (right thumb) in otherwise healthy persons [5]. Interestingly, the nail and matrix volume were higher on the right hand compared to the left hand and higher in men compared to women [5]. However, the hand predominance of the subjects is unknown from this study. The finding of regional variation in nail thickness and thus nail transparency provides further evidence to support the theory why this

Received: November 18, 2019 Accepted: February 10, 2020 Online: May 28, 2020

Correspondence: Steven H. YALE, MD. University of Central Florida College of Medicine, 6850 Lake Nona Blvd, Orlando, FL 32827, United States of America.

Tel: (715) 383-0928 e-mail: steven.yale.md@gmail.com

(c) Copyright 2020 by Istanbul Provincial Directorate of Health - Available online at www.northclinist.com 
sign is limited to the left hand and why some but not all fingers display this finding. Future reports should specify which fingers and hand Quincke sign are seen, had dominance and whether additional maneuvers, such as transilluminating the nail bed, applying uniform pressure, or elevating the hand is required to unmask this sign $[2,3]$. Correlation with the ultrasonographic thickness of the nail and matrix provides additional support to confirm this theory.

Conflict of Interest: No conflict of interest was declared by the authors.

Financial Disclosure: The authors declared that this study has received no financial support.
Authorship Contributions: Concept - SY, HT, ESY, JM; Design SY, HT, ESY, JM; Supervision - SY; Analysis and/or interpretation - SY, HT, ESY, JM; Literature review - SY; Writing - SY, HT, ESY, JM; Critical review - SY, HT, ESY, JM.

\section{REFERENCES}

1. Quincke H. Beobachtungen ueber Capillar- und Venenpuls. Berlin Klin Wschr 1868;5:357-9.

2. Mizuno A, Niwa K. Pocket flashlight-elicited Quincke pulse for aortic dissection diagnosis. Korean J Intern Med 2013;28:631. [CrossRef]

3. Vindhyal MR, Vindhyal S, Boppana VS. Quincke's Pulse. Kans J Med 2019;12:55. [CrossRef]

4. Tice F. The clinical determination and significance of some of the peripheral signs of aortic insufficiency. Illinois Med J 1911;20:271-87.

5. Wollina U, Berger M, Karte K. Calculation of nail plate and nail matrix parameters by $20 \mathrm{MHz}$ ultrasound in healthy volunteers and patients with skin disease. Skin Res Technol 2001;7:60-4. [CrossRef] 